\title{
Diferentes doses de calcário aumentam a absorção de nutrientes pelo pinhão-manso
}

\author{
Different limestone rates increase the nutrient absorptions by the Jatropha curcas
}

\author{
Tatiane Ohland ${ }^{\mathrm{I}}$, Maria do Carmo Lana ${ }^{\mathrm{II}}$, Jucenei Fernando Frandoloso ${ }^{\mathrm{III}}$
}

\begin{abstract}
Resumo
Este trabalho teve por objetivo avaliar se diferentes doses de calcário, aplicadas em subsuperfície, influenciam a absorção de nutrientes em plantas de pinhão-manso (Jatropha curcas L.) em desenvolvimento inicial. O experimento foi realizado em vasos e sob condição de casa de vegetação, em que as plantas de pinhão-manso foram cultivadas em vasos de PVC, divididos em camada superficial $(0-20 \mathrm{~cm})$ e camada subsuperficial $(20-60 \mathrm{~cm})$. A camada superficial recebeu solo corrigido $\left(11,1 \mathrm{t} \mathrm{ha}^{-1}\right.$ de $\mathrm{CaCO}_{3}$ e $\mathrm{MgCO}_{3}$ ) e adubação com NPK. Na camada subsuperficial foi adicionado ao solo as doses de $0 ; 3,7 ; 5,6 ; 7,4 ; 11,1$ e 14,9 $\mathrm{t} \mathrm{ha}{ }^{-1}$ de $\mathrm{CaCO}_{3}$ e $\mathrm{MgCO}_{3}$ na relação molar 4:1. Após 120 dias da emergência das plantas, avaliaram-se os teores e conteúdos de $\mathrm{Al}^{3}, \mathrm{P}, \mathrm{K}, \mathrm{Ca}, \mathrm{Mg}, \mathrm{Zn}, \mathrm{Mn}, \mathrm{Fe}$ e $\mathrm{Cu}$ nas folhas, no caule e nas raízes. Em plantas de pinhão-manso, os teores de $\mathrm{Al}$ são maiores nos tecidos radiculares, seguido das folhas e do caule. Os teores e os conteúdos de $\mathrm{P}, \mathrm{K}, \mathrm{Ca}, \mathrm{Mg}$, Zn e Mn no tecido vegetal são influenciados pelo aumento das doses de calcário no solo. Os teores de $\mathrm{Fe}$ e $\mathrm{Cu}$ nos tecidos vegetais de pinhão-manso sofrem pouca influência das doses crescentes de calcário em subsuperfície.
\end{abstract}

Palavras-chave: Acidez do solo; Calagem; Jatropha curcas

\begin{abstract}
The aim of this work was to evaluate if different limestone rates, applied in subsurface, influence the nutrients absorption in Jatropha curcas L. plants in the initial development. The experiment was carried in pots and under greenhouse conditions, where the J. curcas plants were grown in PVC pots, divided into surface layer $(0-20 \mathrm{~cm})$ and subsurface layer $(20-60 \mathrm{~cm})$. The surface layer received corrected soil $\left(11.1 \mathrm{t} \mathrm{ha}^{-1}\right.$ of $\mathrm{CaCO}_{3}$ and $\mathrm{MgCO}_{3}$ and fertilizers. In the subsurface layer, it was added the doses of 0, 3.7, 5.6, 7.4, 11.1 and $14.9 \mathrm{tha}^{-1} \mathrm{MgCO}_{3}$ and $\mathrm{CaCO}_{3}$ in molar ratio 4:1. After 120 days of plant emergence, the contents and the accumulations of $\mathrm{Al}, \mathrm{P}, \mathrm{K}, \mathrm{Ca}, \mathrm{Mg}, \mathrm{Zn}, \mathrm{Mn}, \mathrm{Fe}$ and $\mathrm{Cu}$ in leaves, stems and roots were evaluated. In J. curcas plants, the $\mathrm{Al}$ contents are higher in root tissues, followed by leaves and stem. The contents and the accumulations of $\mathrm{P}, \mathrm{K}, \mathrm{Ca}, \mathrm{Mg}, \mathrm{Zn}$ and $\mathrm{Mn}$ in the plant tissue are influenced by the increase of limestone rates in the soil. The contents of $\mathrm{Fe}$ and $\mathrm{Cu}$ in the plant tissue of Jatropha curcas were not influenced by the increasing of limestone rates in the subsurface.
\end{abstract}

Keywords: Soil acidity; Liming; Jatropha curcas

\section{Introdução}

O pinhão-manso (Jatropha curcas L.) pertencente à família das Euforbiáceas, a mesma família da mamona e seringueira, planta nativa das Américas e disseminada em regiões tropicais e subtropicais (DIVAKARA et al., 2010). É uma cultura rústica e perene, que se adaptada às mais diversas condições edafoclimáticas, indicada para solos de baixa fertilidade natural (SATO et al., 2009). Para Lima et al. (2012), o cultivo do pinhão-manso é considerado promissor na região nordeste do Brasil, tendo em

Engenheira Agrônoma, Dra ${ }^{\text {. }}$, Professora Adjunta do Centro de Ciências Agrárias, Universidade Estadual do Oeste do Paraná, Rua Pernambuco, 1777, CEP 85960-000, Marechal Cândido Rondon (PR), Brasil. tatianeohland@hotmail.com (ORCID: 0000-0003-2938-4397)

Engenheira Agrônoma, Dr ${ }^{\mathrm{a}}$., Professora Associada do Centro de Ciências Agrárias, Universidade Estadual do Oeste do Paraná, Rua Pernambuco, 1777, CEP 85960-000, Marechal Cândido Rondon (PR), Brasil. mariac.lana@ hotmail.com (ORCID: 0000-0001-9858-2499)

III Engenheiro Agrônomo, Dr., Técnico Laboratorista do Centro de Ciências Agrárias, Universidade Estadual do Oeste do Paraná, Rua Pernambuco, 1777, CEP 85960-000, Marechal Cândido Rondon (PR), Brasil. juceneiff@hotmail.com (ORCID: 0000-0002-4254-3527) 
vista as condições edafoclimáticas exigidas para o pleno desenvolvimento da cultura. Além disso, a extração de óleo das sementes do pinhão-manso aumentou a sua visibilidade comercial, demonstrando o seu potencial para a produção de biodiesel (LIMA et al., 2012; LAVIOLA et al., 2014). De acordo com Virgens et al. (2017), o teor de óleo das sementes dessa espécie varia entre 50 e $60 \%$.

Nos últimos anos, o consumo de biodiesel no Brasil aumentou a partir da obrigatoriedade da adição percentual crescente ao óleo diesel comercializado (BRASIL, 2016). A partir de março de 2018, passou a vigorar a mistura obrigatória de $10 \%$ de biodiesel ao óleo diesel que é comercializado, aumentando o consumo de biodiesel no país. Em 2017 foram consumidos 4,29 bilhões de litros de biodiesel e, com a antecipação da mistura, a expectativa é que a demanda do biodiesel cresça em 1 bilhão de litros em 2018 (BRASIL, 2018). Essa remodelação no abastecimento energético brasileiro tem incorporado e revelado o interesse em algumas espécies agrícolas com potencial para produção de biodiesel, buscando diversificar a produção de matéria-prima.

Apesar do pinhão-manso ser considerada uma planta rústica e de baixa exigência nutricional, para atingir altas produtividades de frutos e viabilidade econômica de produção, é necessária boa disponibilidade de água, solos férteis e com boas condições físicas. Um dos principais fatores restritivos para os cultivos agrícolas nos trópicos está relacionado à acidez dos solos (MACEDO et al., 2011). Em solos com pH menor que 5,0, a dissolução das formas sólidas de alumínio (Al) tende a aumentar, ocorrendo formas iônicas na solução do solo, tornando-se um fator limitante ao crescimento das plantas. O sintoma mais evidente do efeito nocivo dos níveis tóxicos de $\mathrm{Al}$ é a redução no desenvolvimento normal das raízes, inibindo o seu crescimento e bloqueando os mecanismos de aquisição e transporte de nutrientes (MIGUEL et al., 2010). Um fator importante a ser considerado sob condições de campo é a adubação e a correção quanto à acidez na camada superficial, enquanto que a subsuperficial permanece nas condições naturais do solo, apresentando muitas vezes, alta saturação por $\mathrm{Al}$ e baixa saturação por bases (ROSSATO et al., 2009), comprometendo o desenvolvimento das culturas.

A utilização do pinhão-manso para a produção de biodiesel é viável, em função do alto teor de óleo presente nas sementes e o crescimento rápido (LIMA et al., 2012). Por outro lado, há alguns problemas que precisam ser contornados, como a seleção de métodos de extração adequados, seleção genética de cultivares e técnicas para produção de mudas em larga escala. Ressaltando que a busca constante pelos conhecimentos necessários ao cultivo dessa planta é sempre presente, principalmente no que diz respeito ao desenvolvimento inicial, a produção e a produtividade. Assim, tornam-se necessários estudos que visam avaliar o efeito do Al presente no solo sobre o desenvolvimento desta cultura. Desta forma, o presente trabalho tem por objetivo avaliar se doses crescentes de calcário, aplicados em subsuperfície, influenciam na absorção de nutrientes em plantas de pinhão-manso em desenvolvimento inicial.

\section{Material e métodos}

O presente experimento foi conduzido em casa de vegetação localizada no município de Marechal Cândido Rondon - PR. O cultivo de pinhão-manso foi realizado em vasos constituídos de coluna de PVC (policloreto de vinil) com $15 \mathrm{~cm}$ de diâmetro e $60 \mathrm{~cm}$ de altura, subdivididos em camada superficial $(0-20 \mathrm{~cm})$ e camada subsuperficial $(20-60 \mathrm{~cm})$, ambas unidas por fita adesiva, fechada na base com tampa de PVC com quatro furos. Os vasos foram preenchidos com solo, coletado em 0-15 cm de profundidade, do tipo Latossolo Vermelho Distroférrico típico (SANTOS et al., 2018), com 474, 362 e $164 \mathrm{~g} \mathrm{~kg}^{-1}$ de argila, silte e areia, respectivamente.

O delineamento experimental utilizado foi em blocos casualizados, composto por cinco tratamentos e quatro repetições. As doses de carbonatos de cálcio e magnésio correspondem a 0 ; 3,$7 ; 5,6 ; 7,4 ; 11,1$ e $14,9 \mathrm{t} \mathrm{ha}^{-1}$, ou seja, $0 ; 0,5 ; 0 ; 75 ; 1,0 ; 1,5$ e 2,0 vezes a necessidade de calagem para elevar a saturação por bases a $60 \%$. As porções de solo receberam calagem diferencial, que constitui na mistura de carbonatos de cálcio e de magnésio p.a., na relação molar 4:1, resultando em diferentes saturações de Al. Após a calagem, o solo foi umedecido e incubado em sacos plásticos por 30 dias. Após este período, as amostras de solo foram analisadas quanto às características químicas (Tabela 1). 


\section{Tabela 1 - Características químicas das amostras de solo após a incubação com diferentes} doses de calcário.

Table 1 - Chemical characteristics of soil samples after incubation with different limestone rates.

\begin{tabular}{|c|c|c|c|c|c|c|c|c|}
\hline Doses & pH & $\mathbf{K}$ & Ca & Mg & Al & $\mathbf{H}+\mathbf{A l}$ & CTC & $\mathbf{P}$ \\
\hline $\mathbf{t ~ h a}^{-1}$ & $\mathrm{CaCl}_{2}$ & \multicolumn{6}{|c|}{ - } & $\mathrm{mg} \mathrm{dm}^{-3}$ \\
\hline 0,0 & 3,90 & 0,50 & 1,60 & 0,40 & 2,40 & 9,30 & 11,80 & 18,40 \\
\hline 3,7 & 4,30 & 0,60 & 3,60 & 0,90 & 0,80 & 7,50 & 12,60 & 17,10 \\
\hline 5,6 & 4,60 & 0,60 & 4,40 & 1,10 & 0,20 & 4,80 & 10,90 & 17,80 \\
\hline 7,4 & 4,60 & 0,60 & 5,30 & 1,30 & 0,10 & 5,40 & 12,60 & 18,10 \\
\hline 11,1 & 4,90 & 0,60 & 7,70 & 1,90 & 0,00 & 3,70 & 13,90 & 18,30 \\
\hline 14,8 & 5,10 & 0,40 & 9,60 & 2,20 & 0,00 & 3,20 & 15,40 & 18,60 \\
\hline Doses de calcário & M.O. & $\mathrm{V}$ & $\mathrm{m}$ & $\mathrm{Zn}$ & $\mathrm{Fe}$ & $\mathrm{Mn}$ & $\mathrm{Cu}$ & \\
\hline t ha $\mathbf{h}^{-1}$ & $\mathrm{~g} \mathrm{dm}^{-3}$ & \multicolumn{2}{|c|}{-----\%"---- } & \multicolumn{4}{|c|}{---------------'mg dm³-'-------------- } & \\
\hline 0,0 & 39,60 & 21,19 & 48,98 & 3,10 & 38,00 & 64,00 & 5,50 & \\
\hline 3,7 & 36,90 & 40,48 & 13,56 & 2,90 & 36,00 & 51,00 & 5,10 & \\
\hline 5,6 & 41,00 & 55,96 & 3,17 & 2,90 & 32,00 & 59,00 & 5,20 & \\
\hline 7,4 & 36,20 & 57,14 & 1,37 & 2,90 & 31,00 & 49,00 & 5,40 & \\
\hline 11,1 & 37,60 & 73,38 & 0,00 & 2,70 & 32,00 & 62,00 & 4,80 & \\
\hline 14,8 & 38,30 & 79,22 & 0,00 & 2,30 & 38,00 & 65,00 & 5,30 & \\
\hline
\end{tabular}

Em que: $\mathrm{CaCl}_{2}=$ cloreto de cálcio; $\mathrm{CTC}$ = capacidade de troca de cátions; M.O. = matéria orgânica do solo; $\mathrm{V}=$ saturação por bases; $\mathrm{m}$ = saturação por alumínio.

Os vasos foram preparados da seguinte forma: na camada subsuperficial foi colocado $7,06 \mathrm{dm}^{3}$ de solo correspondente às diferentes saturações por $\mathrm{Al}$ e camada superficial todos os vasos receberam $3,53 \mathrm{dm}^{3}$ de solo corrigido com 1,5 vezes a necessidade de calagem, que correspondeu a 11,1 $\mathrm{t} \mathrm{ha}^{-1}$.

A semeadura do pinhão-manso foi realizada com quatro sementes por vaso, após 10 dias da emergência foi realizado o desbaste, deixando-se apenas uma planta por vaso. A adubação do solo foi realizada na camada superficial, utilizando-se $170 \mathrm{mg} \mathrm{dm}^{-3} \mathrm{de} \mathrm{N}$ (ureia), $296 \mathrm{mg} \mathrm{dm}^{-3} \mathrm{de} \mathrm{P}$ (superfosfato simples) e $200 \mathrm{mg} \mathrm{dm}^{-3}$ de K (cloreto de potássio). Realizaram-se duas adubações nitrogenadas de cobertura, aos 45 e 90 dias após a emergência, utilizando-se em cada aplicação $100 \mathrm{mg} \mathrm{dm}^{-3} \mathrm{de} \mathrm{N}$ (ureia).

Após 120 dias da emergência, as plantas foram cortadas na altura do colo e a parte aérea separada em caule e folhas. Os vasos foram desmontados para a retirada do sistema radicular, mediante lavagem com água corrente e auxílio de peneira. As raízes foram separadas em raízes superficiais $(0-20 \mathrm{~cm}$ de profundidade) e raízes subsuperficiais $(20-60 \mathrm{~cm}$ de profundidade). As partes das plantas (folhas, caule e raízes) foram acondicionadas em sacos de papel, colocadas em estufa com circulação forçada de ar a $65^{\circ} \mathrm{C}$, para secagem até peso constante e posterior quantificação dos teores de nutrientes.

Foram determinados os teores de fósforo $(\mathrm{P})$, potássio $(\mathrm{K})$, cálcio $(\mathrm{Ca})$, magnésio $(\mathrm{Mg})$, zinco $(\mathrm{Zn})$, manganês $(\mathrm{Mn})$, ferro $(\mathrm{Fe})$, cobre $(\mathrm{Cu})$ e alumínio ( $\mathrm{Al})$. Foram utilizadas amostras de 0,2 gramas de tecido vegetal (folhas+pecíolos, caule e raízes) secas e moídas, que foram mineralizadas por digestão nítricoperclórica na proporção de 3:1. Nos extratos, o P foi determinado pelo método do ácido ascórbico; o $\mathrm{K}$, por fotometria de emissão de chama; $\mathrm{Ca}, \mathrm{Mg}, \mathrm{Zn}, \mathrm{Mn}, \mathrm{Fe}, \mathrm{Cu}$ por espectrofotometria de absorção atômica e Al pelo método espectrofotométrico com eriocromo cianina R (SILVA, 2009). A determinação 
do conteúdo de nutrientes foi obtida multiplicando-se os teores dos nutrientes das diferentes partes da planta (folhas, caule e raízes) pelos respectivos valores de massa de matéria seca. Após, os dados obtidos foram submetidos à análise de variância e de regressão.

\section{Resultados e discussão}

A alta saturação por Al em subsuperfície (20-60 cm de profundidade) influenciou os teores de $\mathrm{Al}$ nas folhas e no caule (Tabela 2). O teor de Al nas folhas atingiu o ponto de mínimo com a dose de calcário de 8,34 $\mathrm{t} \mathrm{ha}^{-1}$. Entretanto, o teor de $\mathrm{Al}$ no caule aumentou conforme houve o aumento das doses de calcário. Foi observada maior concentração de $\mathrm{Al}$ nas raízes do que na parte aérea, em todas as doses de calcário utilizadas, sendo que o teor de $\mathrm{Al}$ das raízes subsuperficiais foi 2,4 vezes maior que o teor nas raízes superficiais (0-20 cm de profundidade) (Tabela 2). No entanto, o conteúdo de $\mathrm{Al}$ nas folhas apresentou ajuste quadrático, decrescendo até a dose de $8,25 \mathrm{t} \mathrm{ha}^{-1}$ (Tabela 2) e nas raízes subsuperficiais o conteúdo de $\mathrm{Al}$ também apresentou resposta quadrática, porém, aumentando até a dose de 12,33 t ha ${ }^{-1}$.

Tabela 2 - Teor e conteúdo de alumínio em folhas (Al-Folha), caule (Al-Caule), raízes superficiais $\left(A 1-\right.$ Raiz $\left._{1}\right)$ e raízes subsuperficiais $\left(A 1-\right.$ Raiz $\left._{2}\right)$ em função de doses de calcário em subsuperfície.

Table 2 - Aluminum content and accumulation in leaves (Al-Leaf), stem (Al-Stem), surface roots $\left(\right.$ Root $\left._{1}\right)$ and subsurface roots $\left(\right.$ Root $\left._{2}\right)$ in function of limestone rates in subsurface.

\begin{tabular}{|c|c|c|c|c|c|c|c|}
\hline \multirow{3}{*}{$\begin{array}{c}\text { Partes da } \\
\text { planta }\end{array}$} & \multicolumn{6}{|c|}{ Doses de calcário $\left(\mathrm{t} \mathrm{ha}^{-1}\right)$} & \multirow{3}{*}{ Equação } \\
\hline & 0,0 & 3,7 & 5,6 & 7,1 & 11,1 & 14,8 & \\
\hline & \multicolumn{6}{|c|}{ Teor $\left(\mathrm{mg} \mathrm{kg}^{-1}\right)$} & \\
\hline Al-Folha & 481,89 & 387,66 & 292,65 & 326,63 & 387,13 & 366,43 & $\mathrm{y}=429,10-20,68 \mathrm{x}+1,24 \mathrm{x}^{2^{*}} \mathrm{R}^{2}=0,48$ \\
\hline Al-Caule & 115,37 & 104,62 & 122,53 & 120,14 & 182,24 & 186,62 & $y=108,40+0,35 x+0,38 x^{2^{*}} R^{2}=0,86$ \\
\hline Al-Raiz & 948,57 & 1280,97 & 1310,43 & 949,76 & 1464,49 & 1049,68 & $\mathrm{y}=1167,32^{\mathrm{ns}}$ \\
\hline \multirow[t]{2}{*}{$\mathrm{Al}^{-\mathrm{Raiz}_{2}}$} & 2850,24 & 2605,41 & 2767,44 & 2838,69 & 2873,33 & 2837,90 & $\mathrm{y}=2795,50^{\mathrm{ns}}$ \\
\hline & \multicolumn{6}{|c|}{ Conteúdo (mg/planta) } & \\
\hline Al-Folha & 6,51 & 5,50 & 3,56 & 3,81 & 4,16 & 5,23 & $\mathrm{y}=6,69-0,66 \mathrm{x}+0,04 \mathrm{x}^{2 * *} \mathrm{R}^{2}=0,85$ \\
\hline Al-Caule & 4,79 & 4,12 & 3,88 & 4,00 & 5,28 & 5,73 & $\mathrm{y}=4,63^{\mathrm{ns}}$ \\
\hline Al-Raiz & 13,39 & 18,24 & 16,60 & 12,38 & 17,21 & 12,68 & $\mathrm{y}=15,08^{\mathrm{ns}}$ \\
\hline $\mathrm{Al}-\mathrm{Raiz}_{2}$ & 5,41 & 6,67 & 8,81 & 10,08 & 8,07 & 9,26 & $\mathrm{y}=5,32+0,74 \mathrm{x}-0,03 \mathrm{x}^{2^{*}} \mathrm{R}^{2}=0,71$ \\
\hline
\end{tabular}

Em que: ${ }^{\text {ns }}=$ não significativo; $;=$ significativo a $1 \%$ de probabilidade; ${ }^{*}=$ significativo a $5 \%$ de probabilidade pelo Teste $\mathrm{F} ;$ Raiz $_{1}=$ raízes superficiais; Raiz $_{2}=$ raízes subsuperficiais

Estes resultados evidenciam que o pinhão-manso acumula $\mathrm{Al}$, preferencialmente, no sistema radicular, sendo menor a quantidade transportada para a parte aérea. Fato também constatado por Steiner et al. (2012) em plantas de pinhão-manso, sob solução nutritiva contento Al. Assim, para se adaptar às condições locais do solo com elevada acidez, diferentes espécies de plantas desenvolveram mecanismos de tolerância ao Al. Estes mecanismos de tolerância distinguem-se em duas classes principais: aqueles que atuam no sentido de impedir a entrada do $\mathrm{Al}$ pela raiz e aqueles que permitem a planta acumular o Al em locais específicos na planta (CONCEIÇÃO et al., 2008). No presente trabalho, não foram observados visualmente sintomas de toxidez de $\mathrm{Al}$ na parte aérea.

Não houve efeito das doses de calcário sobre os teores de P, K e Ca nas folhas, P, Ca e Mg nas raízes superficiais e para $\mathrm{P}$ e K nas raízes subsuperficiais (Tabela 3). Steiner et al. (2012) verificaram que a atividade do $\mathrm{Al}$ em solução nutritiva, não afeta o teor de $\mathrm{P}$ em raízes de pinhão-manso, porém, $\mathrm{o}$ aumento da atividade de $\mathrm{Al}$ reduz os teores de $\mathrm{P}$ nas folhas. A correção do solo na superfície manteve 
os teores de $\mathrm{Mg}$ constantes nas raízes superficiais. De modo geral, a calagem proporciona aumento no teor de $\mathrm{Mg}$ no solo, resultando consequentemente em maior absorção deste nutriente, como observado no teor de Mg nas raízes subsuperficiais que aumenta até a dose de 13,50 t ha-1.

Tabela 3 - Teor e conteúdo de fósforo $(\mathrm{P})$, potássio $(\mathrm{K})$, cálcio $(\mathrm{Ca})$ e magnésio $(\mathrm{Mg})$ em folhas, caule, raízes superficiais $\left(\operatorname{Raiz}_{1}\right)$ e raízes subsuperficiais $\left(\operatorname{Raiz}_{2}\right)$ em função de doses de calcário em subsuperfície.

Table 3 - Content and accumulation of phosphorus $(\mathrm{P})$, potassium $(\mathrm{K})$, calcium $(\mathrm{Ca})$ and magnesium $(\mathrm{Mg})$ in leaves, stem, surface roots $\left(\right.$ Root $\left._{1}\right)$ and subsurface roots $\left(\right.$ Root $\left._{2}\right)$ in function of limestone rates in subsurface.

\begin{tabular}{|c|c|c|c|c|c|c|c|}
\hline \multirow{3}{*}{$\begin{array}{l}\text { Partes da } \\
\text { planta }\end{array}$} & \multicolumn{6}{|c|}{ Doses de calcário $\left(\mathrm{t} \mathrm{ha}^{-1}\right)$} & \multirow{3}{*}{ Equação } \\
\hline & 0,0 & 3,7 & 5,6 & 7,1 & 11,1 & 14,8 & \\
\hline & \multicolumn{6}{|c|}{ Teor $\left(\mathrm{g} \mathrm{kg}^{-1}\right)$} & \\
\hline P-Folha & 1,87 & 1,83 & 2,01 & 1,98 & 2,04 & 2,12 & $\mathrm{y}=1,97^{\mathrm{ns}}$ \\
\hline P-Caule & 1,08 & 1,03 & 1,25 & 1,18 & 2,04 & 2,26 & $\mathrm{y}=0,82+0,09 \mathrm{x}^{* *} \mathrm{R}^{2}=0,84$ \\
\hline P-Raiz 1 & 1,22 & 1,01 & 1,03 & 0,98 & 1,08 & 1,21 & $y=1,09^{\text {ns }}$ \\
\hline P-Raiz 2 & 1,32 & 1,30 & 1,28 & 1,42 & 1,37 & 1,38 & $\mathrm{y}=1,30^{\mathrm{ns}}$ \\
\hline K-Folha & 18,69 & 17,06 & 18,50 & 19,31 & 17,38 & 19,25 & $\mathrm{y}=18,36^{\mathrm{ns}}$ \\
\hline K-Caule & 20,69 & 17,06 & 18,00 & 18,19 & 28,19 & 31,00 & $\mathrm{y}=19,71-0,85 \mathrm{x}+0,17 \mathrm{x}^{2^{* *}} \mathrm{R}^{2}=0,89$ \\
\hline K-Raiz ${ }_{1}$ & 23,69 & 17,81 & 18,19 & 18,00 & 17,88 & 20,56 & $y=23,26-1,44 x+0,09 x^{2 *} R^{2}=0,91$ \\
\hline K-Raiz 2 & 36,13 & 34,50 & 38,75 & 36,88 & 31,06 & 34,38 & $\mathrm{y}=35,23^{\mathrm{ns}}$ \\
\hline Ca-Folha & 12,59 & 17,38 & 17,97 & 22,92 & 18,14 & 14,73 & $\mathrm{y}=17,28^{\mathrm{ns}}$ \\
\hline Ca-Caule & 1,75 & 7,76 & 7,33 & 8,85 & 11,96 & 12,54 & $\mathrm{y}=3,46+0,70 \mathrm{x}^{* *} \mathrm{R}^{2}=0,89$ \\
\hline Ca-Raiz 1 & 2,78 & 2,81 & 3,33 & 3,51 & 3,15 & 3,91 & $\mathrm{y}=3,25^{\mathrm{ns}}$ \\
\hline $\mathrm{Ca}_{\mathrm{Raiz}}$ & 3,74 & 7,40 & 14,08 & 11,72 & 9,93 & 9,85 & $\mathrm{y}=3,77+1,85 \mathrm{x}-0,10 \mathrm{x}^{2 * *} \mathrm{R}^{2}=0,72$ \\
\hline Mg-Folha & 4,72 & 5,03 & 5,13 & 6,27 & 6,02 & 7,20 & $\mathrm{y}=4,57+0,16 \mathrm{x}^{* *} \mathrm{R}^{2}=0,86$ \\
\hline Mg-Caule & 2,66 & 2,17 & 2,06 & 2,22 & 3,45 & 3,91 & $\mathrm{y}=2,55-0,15 \mathrm{x}+0,02 \mathrm{x}^{2 * *} \mathrm{R}^{2}=0,90$ \\
\hline Mg-Raiz $_{1}$ & 3,88 & 3,03 & 3,51 & 2,77 & 3,46 & 3,91 & $\mathrm{y}=3,43^{\mathrm{ns}}$ \\
\hline \multirow[t]{2}{*}{$\mathrm{Mg}^{\mathrm{Raiz}}{ }_{2}$} & 4,93 & 5,72 & 8,54 & 8,00 & 7,00 & 8,38 & $\mathrm{y}=4,93+0,54 \mathrm{x}-0,02 \mathrm{x}^{2^{*}} \mathrm{R}^{2}=0,63$ \\
\hline & \multicolumn{6}{|c|}{ Conteúdo (mg/planta) } & \\
\hline P-Folha & 28,82 & 25,71 & 23,95 & 22,76 & 21,49 & 30,18 & $\mathrm{y}=29,75-1,89 \mathrm{x}+0,12 \mathrm{x}^{2^{* *}} \mathrm{R}^{2}=0,81$ \\
\hline P-Caule & 44,54 & 40,60 & 39,95 & 39,28 & 58,65 & 68,06 & $y=43,83-1,93 x+0,25 x^{2 * *} R^{2}=0,93$ \\
\hline P-Raiz 1 & 15,16 & 14,51 & 12,94 & 14,10 & 12,88 & 14,43 & $\mathrm{y}=14,00^{\mathrm{ns}}$ \\
\hline $\mathrm{P} \mathrm{Raiz}_{2}$ & 2,51 & 3,31 & 4,06 & 4,66 & 4,03 & 4,47 & $\mathrm{y}=2,49+0,35 \mathrm{x}-0,02 \mathrm{x}^{2^{* *}} \mathrm{R}^{2}=0,84$ \\
\hline K-Folha & 287,53 & 240,21 & 219,68 & 222,02 & 218,75 & 272,92 & $\mathrm{y}=289,59-18,58 \mathrm{x}+1,16 \mathrm{x}^{2^{* * *}} \mathrm{R}^{2}=0,97$ \\
\hline K-Caule & 847,44 & 666,51 & 572,45 & 605,73 & 814,85 & 940,36 & $y=831,34-65,16 x+5,06 x^{2^{* *}} R^{2}=0,89$ \\
\hline K-Raiz & 334,76 & 255,46 & 229,47 & 238,35 & 215,19 & 245,52 & $\mathrm{y}=332,10-23,67 \mathrm{x}+1,21 \mathrm{x}^{2^{*}} \mathrm{R}^{2}=0,97$ \\
\hline K-Raiz ${ }_{2}$ & 77,33 & 88,67 & 111,60 & 118,53 & 96,84 & 108,86 & $y=77,08+6,75 x-0,33 x^{2^{*}} R^{2}=0,62$ \\
\hline Ca-Folha & 193,61 & 246,84 & 213,01 & 262,03 & 191,94 & 206,11 & $\mathrm{y}=218,92^{\mathrm{ns}}$ \\
\hline Ca-Caule & 76,63 & 322,08 & 244,35 & 261,37 & 371,50 & 424,61 & $\mathrm{y}=140,15+29,32 \mathrm{x}^{* *} \mathrm{R}^{2}=0,78$ \\
\hline Ca-Raiz 1 & 39,75 & 40,28 & 41,99 & 46,23 & 37,57 & 46,62 & $\mathrm{y}=42,07^{\mathrm{ns}}$ \\
\hline Ca-Raiz 2 & 7,25 & 18,86 & 39,78 & 34,07 & 28,76 & 29,31 & $\mathrm{y}=7,14+5,94 \mathrm{x}-0,31 \mathrm{x}^{2 * *} \mathrm{R}^{2}=0,76$ \\
\hline Mg-Folha & 72,59 & 71,83 & 60,62 & 60,28 & 64,21 & 101,37 & $y=77,08-5,61 x+0,47 x^{2 *} R^{2}=0,84$ \\
\hline Mg-Caule & 100,21 & 76,06 & 65,53 & 74,22 & 109,22 & 129,13 & $y=96,94-8,13 x+0,72 x^{2 * *} R^{2}=0,90$ \\
\hline Mg-Raiz $_{1}$ & 46,79 & 43,19 & 48,65 & 36,63 & 41,21 & 46,53 & $y=43,83^{\text {ns }}$ \\
\hline${\mathrm{Mg}-\mathrm{Raiz}_{2}}_{2}$ & 7,99 & 13,09 & 24,07 & 24,80 & 20,36 & 27,29 & $\mathrm{y}=7,94+2,75 \mathrm{x}-0,11 \mathrm{x}^{2 * *} \mathrm{R}^{2}=0,77$ \\
\hline
\end{tabular}

Em que: ${ }^{\text {ns }}=$ não significativo $;=$ significativo a $1 \%$ de probabilidade; ${ }^{* *}=$ significativo a $5 \%$ de probabilidade pelo Teste $\mathrm{F}$; Raiz $_{1}=$ raízes superficiais; Raiz $_{2}$ = raízes subsuperficiais

Observou-se resposta quadrática negativa para o teor de $\mathrm{K}$ no caule e nas raízes 
superficiais e para o teor de $\mathrm{Mg}$ no caule, com redução dos teores até as doses de 2,5; 8,0 e 3,75 $\mathrm{t} \mathrm{ha} \mathrm{h}^{-1}$, respectivamente. Para o teor de $\mathrm{Ca}$, em subsuperfície, verificou-se ajuste quadrático, com aumento do teor deste elemento até a dose de $9,25 \mathrm{t} \mathrm{ha}^{-1}$. Houve resposta linear crescente em relação às doses de calcário para os teores de $\mathrm{P}$ e Ca no caule e $\mathrm{Mg}$ nas folhas (Tabela 3). A redução na concentração de $\mathrm{P}$ no caule na ausência da calagem pode estar associado ao seu acúmulo nas raízes, evidenciando a ocorrência de precipitação de fosfato de $\mathrm{Al}$ nos tecidos radiculares e a interferência na translocação deste elemento (MIGUEL et al., 2010).

Outro fator que influenciou no menor teor $\mathrm{P}$ no caule está relacionado ao maior desenvolvimento das plantas nas menores doses de calcário, promovendo um efeito de diluição do $\mathrm{P}$ no tecido, uma vez que o conteúdo de $\mathrm{P}$ no caule diminuiu com a calagem até a dose de $3,86 \mathrm{t} \mathrm{ha}^{-1}$. Por outro lado, o teor de P do solo (SOUZA JÚNIOR et al., 2012) e a matéria orgânica (SPERA et al., 2014) contribuem para reduzir a atividade do Al na solução do solo. De acordo com Souza Júnior et al. (2012), o P reage as formas iônicas de Al e de Fe em solos ácidos, formando compostos de composição definida e pouco solúveis.

Não houve efeito das doses de calcário para os conteúdos de Ca nas folhas e para P, Ca e $\mathrm{Mg}$ nas raízes superficiais. Observou-se ajuste quadrático negativo para os conteúdos de $\mathrm{P}$, $\mathrm{K}$ e $\mathrm{Mg}$ nas folhas e caule e também para $\mathrm{K}$ nas raízes superficiais. A calagem aumentou os conteúdos de $\mathrm{P}, \mathrm{K}, \mathrm{Ca}$ e $\mathrm{Mg}$ nas raízes subsuperficiais até as doses de 8,75; 10,22; 9,58 e 12,50 t ha $^{-1}$, respectivamente (Tabela 3 ).

O conteúdo do nutriente nas raízes está relacionado com a produção de matéria seca. Assim, o aumento das doses de calcário em subsuperfície propiciou o desenvolvimento das raízes em profundidade e melhorou sua distribuição nas camadas avaliadas. Diante do exposto, pode-se considerar que as menores doses de calcário, promoveram o maior desenvolvimento radicular superficial, estando relacionado às condições químicas do solo, neste caso, a presença de $\mathrm{Al}$ em subsuperfície.

O aumento da concentração de $\mathrm{Al}$ afeta negativamente o crescimento das raízes de pinhãomanso (LANA et al., 2009; MACEDO et al., 2011). Lana et al. (2009) observaram que plantas de pinhão-manso cultivadas em solução nutritiva contendo $25 \mathrm{mg} \mathrm{L}^{-1}$ de $\mathrm{Al}$, apresentaram redução de 23,$9 ; 23,8 ; 16,0$ e 11,2 \% para produção de matéria seca da parte aérea, número de folhas, área foliar e altura, respectivamente, quando comparado à testemunha $\left(0 \mathrm{mg} \mathrm{L}^{-1}\right)$ e redução de 0,28 $\mathrm{cm}$ no comprimento da raiz primária para cada $\mathrm{mg} \mathrm{L}^{-1}$ de $\mathrm{Al}$ adicionado em solução. $\mathrm{O}$ aumento da atividade do $\mathrm{Al}$, em solução nutritiva, reduz os teores $\mathrm{Ca}$ e $\mathrm{Mg}$ nas folhas e raízes de pinhãomanso, reportando o efeito do $\mathrm{Al}$ na absorção, transporte e utilização destes nutrientes pelas plantas, assim, sob condições de solos ácidos, o Ca cede lugar para o Al no complexo de troca, limitando a absorção de Ca (STEINER et al., 2012).

No presente trabalho, os teores dos nutrientes na planta em solo corrigido, de modo geral, apresentaram seguinte ordem: $\mathrm{K}>\mathrm{Ca}>\mathrm{Mg}>\mathrm{P}>\mathrm{Al}>\mathrm{Fe}>\mathrm{Mn}>\mathrm{Zn}>\mathrm{Cu}$. No entanto, em plantas de pinhão-manso mais desenvolvidas, do primeiro ao quarto cultivo, apresentam a seguinte ordem de acúmulo foliares de nutrientes: $\mathrm{Ca}>\mathrm{K}>\mathrm{Mg}>\mathrm{P}>\mathrm{Mn}>\mathrm{Fe}>\mathrm{Zn}>\mathrm{Cu}$ (LAVIOLA; DIAS, 2008), em que Ca é o nutriente mais exigido para a formação das folhas. Estes autores encontraram teores foliares de 2,8; 13,7; 19,0 e 4,8 $\mathrm{g} \mathrm{kg}^{-1}$ para $\mathrm{P}, \mathrm{K} \mathrm{Ca}$ e $\mathrm{Mg}$, respectivamente. No entanto, para o presente trabalho foram verificados os teores foliares médios de 1,$97 ; 18,36 ; 17,28 \mathrm{~g} \mathrm{~kg}^{-1}$ para $\mathrm{P}, \mathrm{K} \mathrm{Ca}$, respectivamente, e o teor de $\mathrm{Mg}$ variou de 4,57 a 6,94 $\mathrm{g} \mathrm{kg}^{-1}$ em função das doses crescentes de calcário. Assim, composição química e o acúmulo de nutrientes são informações imprescindíveis para se conhecer as exigências nutricionais de uma planta, bem como auxiliar na recomendação de adubação da cultura, que depende das demandas nutricionais das plantas para o desenvolvimento vegetativo e posteriormente reprodutivo.

De modo geral, verifica-se que a camada superficial proporcionou condições para o desenvolvimento da cultura, ressalta-se neste caso que nas condições ambientais experimentais não houve limitação na disponibilidade de água. Por outro lado, o menor desenvolvimento radicular em subsuperfície, sob condições de campo, pode limitar o desenvolvimento da cultura 
em situações de deficit hídrico, principalmente em doses de calcário inferiores a 3,7 $\mathrm{t} \mathrm{ha} \mathrm{h}^{-1}$, em que foram observados os menores conteúdos de $\mathrm{P}, \mathrm{K}, \mathrm{Ca}$ e $\mathrm{Mg}$, indicando assim menor produção de matéria seca de raízes em subsuperfície e consequentemente, menor desenvolvimento das raízes em solo com maior saturação por Al. Em Latossolo Vermelho Distrófico, plantas jovens de pinhão-manso apresentam sinais de estresse hídrico, em teores de água disponível abaixo de $60 \%$ da capacidade de retenção de água no solo (PADILHA et al., 2016). Entretanto, o pinhão-manso consegue manter suas atividades fisiológicas normalizadas quando submetidas ao estresse hídrico, sugerindo assim, sua potencialidade para regiões semiáridas (MOURA et al., 2016).

Não houve efeito das doses de calcário para o teor de Fe nas folhas, Fe e Cu no caule, Zn, $\mathrm{Fe}$ e $\mathrm{Cu}$ nas raízes superficiais e para o teor de $\mathrm{Fe}$ e $\mathrm{Cu}$ nas raízes subsuperficiais. Houve resposta linear decrescente para o teor de $\mathrm{Zn}$ e de $\mathrm{Mn}$ nas folhas e para o teor $\mathrm{Mn}$ no caule e nas raízes superficiais e subsuperficiais conforme o aumento das doses de calcário aplicadas. Os teores de $\mathrm{Mn}$ no tecido vegetal reduziram severamente a partir da dose de 3,7 $\mathrm{t} \mathrm{ha}^{-1}$ de calcário (Tabela 4). Foram observados os teores de 28,6; 8,9 e 40,8 $\mathrm{mg} \mathrm{kg}^{-1}$ para o teor de $\mathrm{Mn}$ no caule, raízes superficiais e subsuperficiais, respectivamente, para a dose de $14,8 \mathrm{t} \mathrm{ha}^{-1}$ de calcário.

Tabela 4 - Teor e conteúdo de zinco $(\mathrm{Zn})$, manganês $(\mathrm{Mn})$, ferro $(\mathrm{Fe})$ e cobre $(\mathrm{Cu})$ em folhas, caule, raízes superficiais $\left(\operatorname{Raiz}_{1}\right)$ e raízes subsuperficiais $\left(\operatorname{Raiz}_{2}\right)$ em função de doses de calcário em subsuperfície.

Table 4 - Content and accumulation of zinc $(\mathrm{Zn})$, manganese $(\mathrm{Mn})$, iron $(\mathrm{Fe})$ and copper $(\mathrm{Cu})$ in leaves, stem, surface roots $\left(\right.$ Root $\left._{1}\right)$ and subsurface roots $\left(\right.$ Root $\left._{2}\right)$ in function of limestone rates in subsurface.

\begin{tabular}{|c|c|c|c|c|c|c|c|}
\hline \multirow{3}{*}{$\begin{array}{c}\text { Partes da } \\
\text { planta }\end{array}$} & \multicolumn{6}{|c|}{ Doses de calcário $\left(\mathrm{t} \mathrm{ha}^{-1}\right)$} & \multirow{3}{*}{ Equação } \\
\hline & 0,0 & 3,7 & 5,6 & 7,1 & 11,1 & 14,8 & \\
\hline & \multicolumn{6}{|c|}{ Teor $\left(\mathrm{mg} \mathrm{kg}^{-1}\right)$} & \\
\hline Zn-Folha & 21,10 & 17,58 & 16,09 & 13,19 & 13,14 & 11,26 & $\mathrm{y}=19,33-0,64 \mathrm{x}^{*} \mathrm{R}^{2}=0,89$ \\
\hline Zn-Caule & 12,25 & 6,76 & 4,21 & 5,40 & 7,72 & 10,87 & $\mathrm{y}=11,90-1,83 \mathrm{x}+0,12 \mathrm{x}^{2^{*}} \mathrm{R}^{2}=0,93$ \\
\hline Zn-Raiz $_{1}$ & 8,97 & 6,73 & 3,80 & 6,03 & 4,11 & 3,00 & $\mathrm{y}=5,44^{\mathrm{ns}}$ \\
\hline $\mathrm{Zn} \mathrm{Raiz}_{2}$ & 17,68 & 9,36 & 11,71 & 11,59 & 10,35 & 11,78 & $y=16,67-1,46 x+0,08 x^{2^{*}} R^{2}=0,70$ \\
\hline Mn-Folha & 354,99 & 291,31 & 159,45 & 143,77 & 137,72 & 80,66 & $\mathrm{y}=321,90-18,06 \mathrm{x}^{* *} \mathrm{R}^{2}=0,82$ \\
\hline Mn-Caule & 329,79 & 167,07 & 48,19 & 30,43 & 61,45 & 28,56 & $\mathrm{y}=236,40-17,79 \mathrm{x}^{* *} \mathrm{R}^{2}=0,63$ \\
\hline Mn-Raiz $_{1}$ & 167,51 & 114,46 & 29,37 & 21,87 & 12,04 & 8,85 & $\mathrm{y}=134,20-10,67 \mathrm{x}^{* *} \mathrm{R}^{2}=0,73$ \\
\hline${\mathrm{Mn}-\mathrm{Raiz}_{2}}_{2}$ & 468,67 & 442,43 & 210,45 & 173,32 & 59,17 & 40,77 & $\mathrm{y}=461,20-32,45 \mathrm{x}^{* *} \mathrm{R}^{2}=0,86$ \\
\hline Fe-Folha & 114,40 & 113,37 & 96,61 & 88,65 & 103,34 & 108,66 & $\mathrm{y}=104,17^{\mathrm{ns}}$ \\
\hline Fe-Caule & 28,99 & 26,12 & 21,03 & 19,71 & 31,71 & 38,55 & $\mathrm{y}=27,68^{\mathrm{ns}}$ \\
\hline $\mathrm{Fe}_{\mathrm{Raiz}}$ & 133,17 & 167,01 & 186,86 & 125,47 & 198,71 & 148,48 & $y=159,95^{\mathrm{ns}}$ \\
\hline $\mathrm{Fe}_{-\mathrm{Raiz}_{2}}$ & 424,62 & 354,65 & 404,46 & 403,91 & 454,58 & 415,07 & $\mathrm{y}=409,55^{\mathrm{ns}}$ \\
\hline $\mathrm{Cu}-\mathrm{Folha}$ & 15,57 & 12,85 & 6,57 & 6,43 & 10,43 & 11,54 & $y=15,92-1,94 x+0,11 x^{2^{* * *}} R^{2}=0,73$ \\
\hline $\mathrm{Cu}-\mathrm{Caule}$ & 7,62 & 6,93 & 4,14 & 4,50 & 5,26 & 6,02 & $\mathrm{y}=5,74^{\mathrm{ns}}$ \\
\hline $\mathrm{Cu}-\mathrm{Raiz}_{1}$ & 8,48 & 5,22 & 6,17 & 3,62 & 5,77 & 3,11 & $\mathrm{y}=5,40^{\mathrm{ns}}$ \\
\hline $\mathrm{Cu}-\mathrm{Raiz}$ & 22.10 & 12.53 & 15.54 & 20,08 & 17,42 & 16,25 & $y=17,32^{n s}$ \\
\hline
\end{tabular}

Continua.... 
Tabela 4 - Conclusão...

Table 4 - Conclusion...

\begin{tabular}{|c|c|c|c|c|c|c|c|}
\hline \multirow{3}{*}{$\begin{array}{c}\text { Partes da } \\
\text { planta }\end{array}$} & \multicolumn{6}{|c|}{ Doses de calcário $\left(\mathrm{t} \mathrm{ha}^{-1}\right)$} & \multirow{3}{*}{ Equação } \\
\hline & 0,0 & 3,7 & 5,6 & 7,1 & 11,1 & 14,8 & \\
\hline & \multicolumn{6}{|c|}{ Teor $\left(\mathrm{mg} \mathrm{kg}^{-1}\right)$} & \\
\hline \multicolumn{8}{|c|}{ Conteúdo (mg/planta) } \\
\hline Zn-Folha & 0,25 & 0,21 & 0,19 & 0,15 & 0,16 & 0,16 & $\mathrm{y}=0,23-0,006 \mathrm{x}^{* *} \mathrm{R}^{2}=0,70$ \\
\hline Zn-Caule & 0,50 & 0,27 & 0,13 & 0,18 & 0,21 & 0,34 & $y=0,49-0,08 x+0,48 x^{2^{* *}} R^{2}=0,94$ \\
\hline $\mathrm{Zn} \mathrm{Raiz}_{1}$ & 0,12 & 0,10 & 0,08 & 0,06 & 0,05 & 0,03 & $y=0,12-0,006 x^{* *} R^{2}=0,96$ \\
\hline $\mathrm{Zn}_{\mathrm{Raiz}}$ & 0,03 & 0,03 & 0,04 & 0,04 & 0,03 & 0,04 & $\mathrm{y}=0,03^{\mathrm{ns}}$ \\
\hline Mn-Folha & 5,45 & 4,09 & 1,89 & 1,66 & 1,40 & 1,14 & $\mathrm{y}=4,64-0,29 \mathrm{x}^{\text {N* }} \mathrm{R}^{2}=0,76$ \\
\hline Mn-Caule & 11,96 & 6,02 & 1,95 & 1,11 & 1,45 & 0,74 & $\mathrm{y}=8,71-0,69 \mathrm{x}^{* *} \mathrm{R}^{2}=0,68$ \\
\hline Mn-Raiz $_{1}$ & 2,37 & 1,64 & 0,45 & 0,29 & 0,14 & 0,11 & $\mathrm{y}=1,92-0,15 \mathrm{x}^{* *} \mathrm{R}^{2}=0,74$ \\
\hline $\mathrm{Mn}-\mathrm{Raiz}_{2}$ & 0,89 & 1,01 & 0,80 & 0,70 & 0,12 & 0,10 & $\mathrm{y}=1,08-0,07 \mathrm{x}^{* * *} \mathrm{R}^{2}=0,83$ \\
\hline Fe-Folha & 1,77 & 1,45 & 1,15 & 1,02 & 1,20 & 1,54 & $\mathrm{y}=1,81-0,17+0,01 \mathrm{x}^{2 * *} \mathrm{R}^{2}=0,93$ \\
\hline Fe-Caule & 1,01 & 0,80 & 0,66 & 0,66 & 1,02 & 1,39 & $\mathrm{y}=1,01-0,11 \mathrm{x}+0,01 \mathrm{x}^{2^{* *}} \mathrm{R}^{2}=0,96$ \\
\hline Fe-Raiz $_{1}$ & 1,89 & 2,39 & 2,05 & 1,78 & 2,01 & 1,97 & $\mathrm{y}=2,01^{\mathrm{ns}}$ \\
\hline $\mathrm{Fe}_{-\mathrm{Raiz}_{2}}$ & 0,79 & 0,91 & 1,18 & 1,44 & 1,28 & 1,35 & $\mathrm{y}=0,75+0,10-0,004 \mathrm{x}^{2^{* *}} \mathrm{R}^{2}=0,80$ \\
\hline Cu-Folha & 0,24 & 0,18 & 0,09 & 0,08 & 0,11 & 0,16 & $\mathrm{y}=0,25-0,04 \mathrm{x}+0,002 \mathrm{x}^{2^{*}} \mathrm{R}^{2}=0,88$ \\
\hline Cu-Caule & 0,36 & 0,27 & 0,19 & 0,12 & 0,16 & 0,20 & $\mathrm{y}=0,37-0,05 \mathrm{x}+0,002 \mathrm{x}^{2^{* *}} \mathrm{R}^{2}=0,91$ \\
\hline $\mathrm{Cu}-\mathrm{Raiz}_{1}$ & 0,09 & 0,09 & 0,07 & 0,06 & 0,08 & 0,06 & $y=0,09-0,001 x^{* *} R^{2}=0,41$ \\
\hline $\mathrm{Cu}-\mathrm{Raiz}_{2}$ & 0,04 & 0,04 & 0,05 & 0,06 & 0,05 & 0,06 & $y=0,04+0,001 x^{* *} R^{2}=0,67$ \\
\hline
\end{tabular}

Em que: ${ }^{\text {ns }}=$ não significativo; ${ }^{* *}=$ significativo a $1 \%$ de probabilidade; ${ }^{*}=$ significativo a $5 \%$ de probabilidade pelo Teste $\mathrm{F}$; Raiz $_{1}$ = raízes superficiais; Raiz $_{2}$ = raízes subsuperficiais

A calagem elevou do pH do solo, o que diminuiu a concentração de Mn disponível no solo e a absorção deste nutriente. Desta forma, a redução das doses de calcário proporcionou aumento no teor de Mn nas raízes subsuperficiais, seguido das folhas e do caule (Tabela 4). Este incremento no teor de $\mathrm{Mn}$ em partes da planta está relacionado aos mecanismos de tolerância ao excesso de Mn. Estes mecanismos têm sido associados à oxidação deste nutriente nas raízes, à restrição na taxa de absorção pelas raízes e ao transporte do excesso de $\mathrm{Mn}$ para as folhas, bem como à distribuição uniforme do Mn nos tecidos vegetais, à maior tolerância interna e à interação com outros nutrientes (LAVRES JUNIOR et al., 2008).

Houve resposta quadrática negativa para o teor de $\mathrm{Zn}$ no caule e nas raízes subsuperficiais e para $\mathrm{Cu}$ nas folhas. O menor teor de $\mathrm{Zn}$ ocorre na dose de 7,5 $\mathrm{t} \mathrm{ha}^{-1}$ para o caule e 9,4 $\mathrm{t} \mathrm{ha}^{-1}$ de calcário nas raízes subsuperficiais. Para o teor de $\mathrm{Cu}$ presente nas folhas, o menor teor é observado na dose de $8,5 \mathrm{t} \mathrm{ha}^{-1}$ de calcário (Tabela 4).

Não houve efeito das doses de calcário para o conteúdo de $\mathrm{Zn}$ nas raízes subsuperficiais e de $\mathrm{Fe}$ nas raízes superficiais. Observou-se ajuste linear decrescente para os conteúdos de Mn em todas as partes da planta, Zn nas folhas e nas raízes superficiais e para conteúdo de $\mathrm{Cu}$ nas raízes superficiais e subsuperficiais. Para os conteúdos de $\mathrm{Fe}$ e $\mathrm{Cu}$ nas folhas e no caule, verificou-se ajuste quadrático negativo e ajuste quadrático positivo para o teor de Fe nas raízes subsuperficiais (Tabela 4).

$\mathrm{O}$ pH do solo, na maioria das vezes, é o principal fator de controle de disponibilidade de micronutrientes para plantas, pois a diminuição do $\mathrm{pH}$ aumenta do teor de micronutrientes no solo (NACHTIGALL; NOGUEIROL; ALLEONI, 2009). Desta forma, a condição de acidez do solo para as menores doses de calcário em subsuperfície (Tabela 1), contribuiu para a maior 
disponibilidade de micronutrientes no solo, principalmente $\mathrm{Zn}$, influenciando na produção de matéria seca. De modo geral, os teores e conteúdos de nutrientes nas folhas e no caule apresentaram comportamento com ajuste quadrático, indicando maior produção de matéria seca de parte aérea em doses de calcário abaixo de $3,7 \mathrm{t} \mathrm{ha}^{-1}$.

Visualmente, a altura de plantas foi maior na ausência de calagem, influenciada possivelmente pelo maior teor de $\mathrm{Zn}$, tanto nas folhas como no caule. De acordo com Maia et al. (2014), a omissão de Zn em plantas de pinhão-manso afeta o comprimento e matéria seca de caules, número de folhas e a produção de massa de matéria seca de raízes.

Os conteúdos de $\mathrm{Zn}$ e $\mathrm{Cu}$ não apresentaram diferenciação na translocação e seguem a ordem de acúmulo de caule>folha>raiz (Tabela 4). Para Chaves et al. (2010), os conteúdos de $\mathrm{Zn}$ e $\mathrm{Cu}$ em plantas de pinhão-manso apresentaram a seguinte ordem: caule $>$ folha $>$ raiz e folha $>$ raiz $>$ caule, respectivamente. Este acúmulo preferencial no caule contribui para a imobilização de Zn (CHAVES et al., 2010) e Cu na vegetação, o que torna o pinhão-manso uma alternativa em programas de fitorremediação, desde que tolere as condições de altas dosagens destes elementos no solo.

Os nutrientes que menos se acumularam em plantas de pinhão-manso foram o $\mathrm{Zn}$ e o Cu, fato também constatado por Laviola e Dias (2008), em diagnose foliar. Entretanto, estes elementos não deixam de ser essenciais para desenvolvimento da cultura, sendo necessário manter à disposição, pelo menos o teor mínimo necessário para tal. Por outro lado, o desenvolvimento das plantas de pinhão-manso é mais comprometido pela deficiência dos macronutrientes, justificado pelas reduções da matéria seca de raiz, caule e folhas e a restrição do crescimento provocada pela omissão de nutrientes apresenta a seguinte ordem: $\mathrm{N}>\mathrm{Mg}>\mathrm{S}>\mathrm{K}>\mathrm{Ca}=\mathrm{P}>\mathrm{Zn}>\mathrm{B}=\mathrm{Fe}$ (MAIA et al., 2014).

\section{Conclusão}

Em plantas de pinhão-manso, os teores de $\mathrm{Al}$ são maiores nos tecidos radiculares, seguido das folhas e em menor quantidade no caule.

Os teores de $\mathrm{P}$ e $\mathrm{K}$ no caule e o teor de $\mathrm{K}$ nas raízes em até $20 \mathrm{~cm}$ de profundidade do solo são influenciados pelas doses crescentes de calcário em subsuperfície, bem como o conteúdo destes nutrientes nas diferentes partes da planta.

Nas raízes de 20-60 cm de profundidade do solo, os teores de $\mathrm{Ca}$ e $\mathrm{Mg}$ aumentam com a utilização de doses de calcário em subsuperfície.

Doses crescentes de calcário de 0 a 14,8 $\mathrm{t} \mathrm{ha}^{-1}$ reduzem os teores de $\mathrm{Zn}$ e Mn na parte aérea e raízes. Os teores de $\mathrm{Fe}$ e $\mathrm{Cu}$ nos tecidos vegetais de pinhão-manso sofrem pouca influência das doses crescentes de calcário em subsuperfície.

\section{Referências}

BRASIL. Lei no 13.263, de 23 de março de 2016. Percentuais de adição de biodiesel ao óleo diesel comercializado no território nacional. Brasília: Presidência da República, 2016. Disponível em: http://www.planalto.gov.br/ccivil_03/_Ato2015-2018/2016/Lei/L13263.htm\#art1. Acesso em: 25 maio 2018.

BRASIL. Ministério de Minas e Energia. Produção de biodiesel atinge 452 milhões de litros, maior volume nos últimos dez anos. Brasília: MME, 2018. Disponível em: http://www.mme.gov. br. Acesso em: 25 maio 2018.

CHAVES, L. H. G. et al. Crescimento, distribuição e acúmulo de cobre e zinco em plantas de pinhão-manso. Revista Ciência Agronômica, Fortaleza, v. 41, n. 2, p. 167-176, 2010.

CONCEIÇÃO, L. D. C. S. et al. Tolerância ao alumínio em plantas: toxicidade, mecanismos e genes em espécies cultivadas. Revista Brasileira de Agrociência, Pelotas, v. 14, n. 3/4, p. 01-10, 2008 . 
DIVAKARA, B. N. et al. Biology and genetic improvement of Jatropha curcas L.: a review. Applied Energy, Amsterdam, v. 87, p. 732-742, 2010.

LANA, M. do C. et al. Tolerância de plântulas de pinhão-manso a toxicidade de alumínio em solução nutritiva. I: desenvolvimento da parte aérea e sistema radicular. Synergismus scyentifica UTFP, Pato Branco, v. 4, n. 1, 2009.

LAVIOLA, B .G. et al. Desempenho agronômico e ganho genético pela seleção de pinhão-manso em três regiões do Brasil. Pesquisa Agropecuária Brasileira, Brasília, v. 49, p. 356-363, 2014.

LAVIOLA, B. G.; DIAS, L. A. S. Teor e acúmulo de nutrientes em folhas e frutos de pinhão manso. Revista Brasileira de Ciência do Solo, Viçosa, MG, v. 32, p. 1969-1975, 2008.

LAVRES JUNIOR, J. et al. Influência genotípica na absorção e na toxidez de manganês em soja. Revista Brasileira de Ciência do Solo, Viçosa, MG, v. 32, p. 173-181, 2008.

LIMA, M. L. B. et al. Pinhão manso como alternativa para produção de biodiesel. Agropecuária Científica no Semi-Árido, Patos, v. 8, n. 4, p. 01-07, 2012.

MACEDO, F. L. et al. Efeito do alumínio em plantas de pinhão-manso (Jatropha curcas L.), cultivadas em solução nutritiva. Semina: Ciências Agrárias, Londrina, v. 32, p. 157-164, 2011.

MAIA, J. T. L. S. et al. Omissão de nutrientes em plantas de pinhão-manso cultivadas em solução nutritiva. Revista Ceres, Viçosa, MG, v. 61, n. 5, p. 723-731, 2014.

MIGUEL, P. S. B. et al. Efeitos tóxicos do alumínio no crescimento das plantas: mecanismos de tolerância, sintomas, efeitos fisiológicos, bioquímicos e controles genéticos. CES Revista, Juiz de Fora, v. 24, p. 13-29, 2010. Disponível em: https://www.cesjf.br/revistas/cesrevista/edicoes/2010/01_ BIOLOGIA_efeitodoaluminio.pdf. Acesso em: 20 out. 2018.

MOURA, A. R. et al. Relações hídricas e solutos orgânicos em plantas jovens de Jatropha curcas L. sob diferentes regimes hídricos. Ciência Florestal, Santa Maria, v. 26, n. 2, p. 345-354, 2016.

NACHTIGALL, G. R.; NOGUEIROL, R. C.; ALLEONI, L. R. F. Extração sequencial de Mn e $\mathrm{Zn}$ em solos em função do pH e adição de cama-de-frango. Revista Brasileira de Engenharia Agrícola e Ambiental, Campina Grande, v. 13, n. 3, p. 240-249, 2009.

PADILHA, N. S. et al. Crescimento inicial do pinhão-manso submetido a diferentes regimes hídrico em Latossolo Vermelho distrófico. Ciência Florestal, Santa Maria, v. 26, n. 2, p. 513-521, 2016.

ROSSATO, O. B. et al. Correction of soil acidity in the subsurface of na oxisol with Sandy loam texture under no-tillage. Revista Brasileira de Ciência do Solo, Viçosa, MG, v. 33, p. 659-667, 2009.

SANTOS, H. G. et al. Sistema brasileiro de classificação de solo. 5. ed. Brasília, DF: EMBRAPA, 2018. $590 \mathrm{p}$.

SATO, M. et al. Cultura de Pinhão-manso (Jatropha curcas L): uso para fins combustíveis e descrição agronômica. Revista Varia Scientia, Cascavel, v. 7, n. 13, p. 47-62, 2009.

SILVA, F. C. (ed.). Manual de análises químicas de solos, plantas e fertilizantes. 2. ed. Brasília: EMBRAPA Informação Tecnológica, 2009.627 p.

SOUZA JÚNIOR, R. F. et al. Frações de fósforo inorgânico do solo e suas correlações com o fósforo quantificado por extratores e pelo milho. Revista Brasileira de Ciência do Solo, Viçosa, MG, v. 36, p. 159-169, 2012.

SPERA, S. T. et al. Atividade do alumínio na solução do solo de um Latossolo Vermelho distrófico submetido ao manejo do solo e de culturas. Nativa, Sinop, v. 2, n. 3, p. 131-137, 2014.

STEINER, F. et al. Effects of aluminum on plant growth and nutrient uptake in young physic nut plants. Semina: Ciências Agrárias, Londrina, v. 33, n. 5, p. 1779-1788, 2012.

VIRGENS, I. O. et al. Revisão: Jatropha curcas L.: aspectos morfofisiológicos e químicos. Brazilian Journal of Food Technology, Campinas, v. 20, p. 01-11, 2017. 